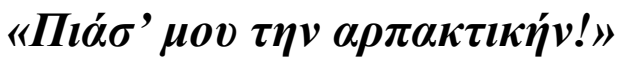

\section{(«Piás’ mou tin arpaktikín»)}

\author{
Lena Kontakou-Pavlidis \\ Hellenic Open University
}

\section{Пєрí $\eta \psi \eta$}

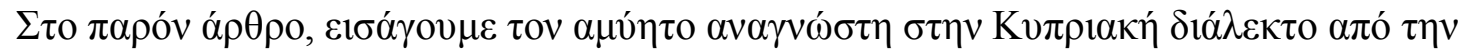

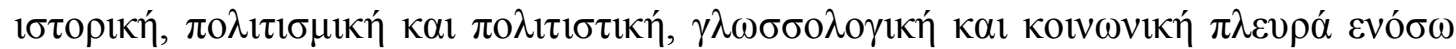

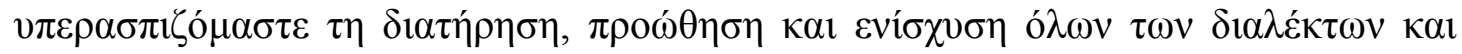

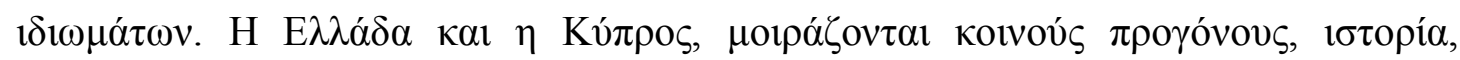

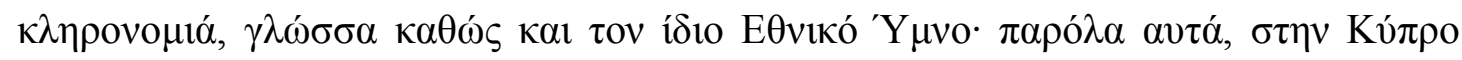

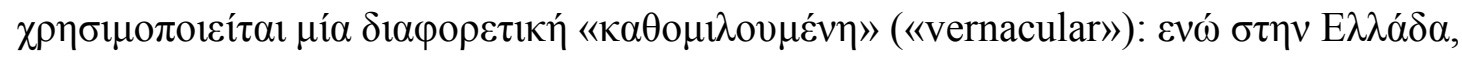

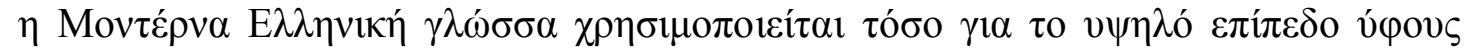

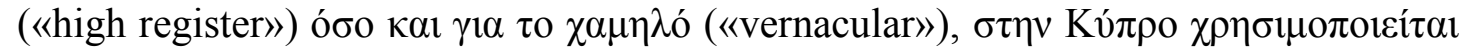

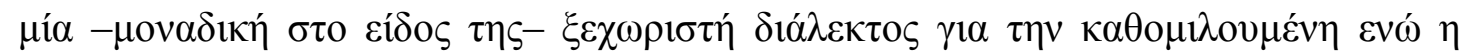

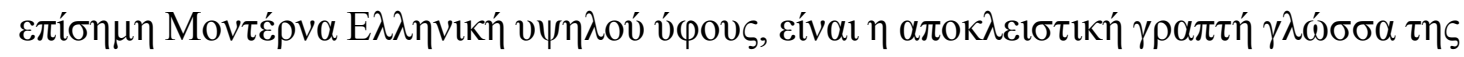

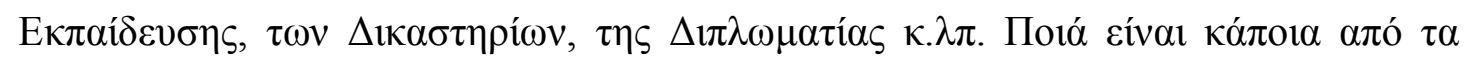

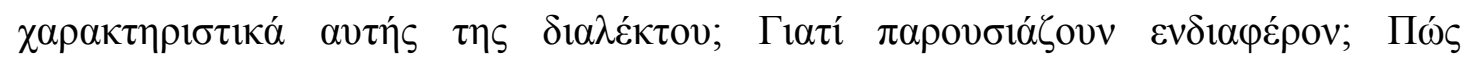

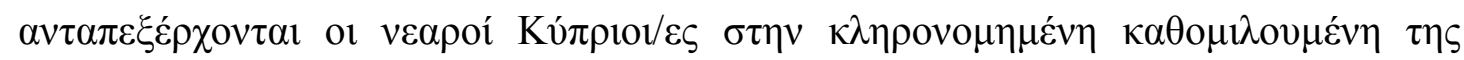

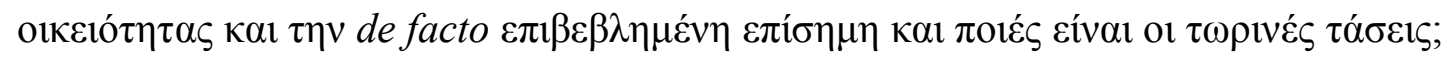

\begin{abstract}
In this article, we present a brief overview of the Cypriot dialect from a historic, cultural, linguistic and social point of view whereas we defend the preservation, promotion and reinforcement of all dialects and idioms. Cyprus and Greece, share common ancestry, history, heritage, language and the same national anthem ; yet, Cyprus uses a different «vernacular»: while in Greece, Modern Greek is being used as a high and a low variety («vernacular» and official) in Cyprus, a one-of-a-kind distinctive dialect is being used; in casual daily verbal communication, the Cypriot dialect is being used while the official standard Modern Greek is being used at schools, Courts and Diplomacy matters; what are some characteristic elements of this dialect?
\end{abstract}


Why are they interesting? How young Cypriots, caught between an inherited vernacular at home and an official at school cope with this de facto and what is the actual tendency?

The Cypriot dialect dates back to the Antiquity and is believed to descend from the Proto-Arcadocypriot Ancient Greek dialect, brought to the island of Cyprus by Arcadians, trying to flee the Dorian invasion back in 1200 B.C. It resembles the Linear B-corpus. According to the Academy of Athens, sole Greek Authority for linguistic categorization, Cypriot is considered as a Southern dialect. Southern dialects, including those of Chios, Samos and the Dodecanese islands, start on the 380 parallel north and are characterized by phonological changes in vowels. It is also considered an «ív $\tau \alpha »$ and a « $\pi$ ó $\theta \varepsilon v »$ («índa»= how, what, "póthen»=where, from where) dialect, a characteristic shared with Crete. Based on Kontosopoulos' (1994:92) criterium of «mutual understanding» Cypriot is a dialect, because it is unintelligible to speakers of Greek, unless previously familiarized. In fact, Francs, Venetians, Arabs, Turks, British have all left an indelible imprint on this language.

An authentic mosaic of the island's history, Cypriot, reflects the smooth incorporation and amalgamation of languages and cultures throughout the years; «O

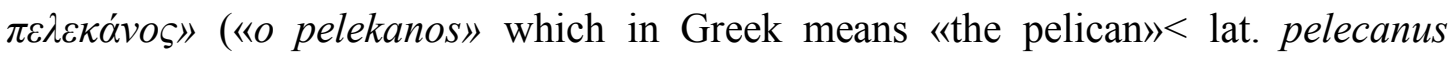
onocrotalus), in Cypriot means «the furniture maker» and comes from Venetian and latin. Other words start with a double consonant, such as

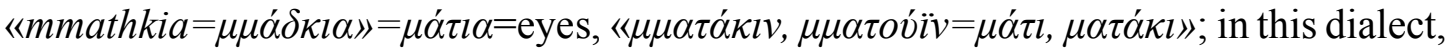
double consonants are particularly stressed when pronounced, resembling the spelling of the modern Spanish Castellano as in «innato» (innate), certainly of latin heritage, or the double $\langle s s\rangle$ pronounced as $\langle s h s h\rangle$ in «diakossia» (200), «triakossia» (300) etc. Another characteristic is the combination of the delta $\langle\delta\rangle$ or the theta $\langle\theta »$ with the

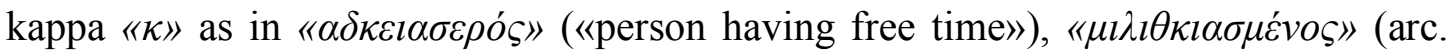

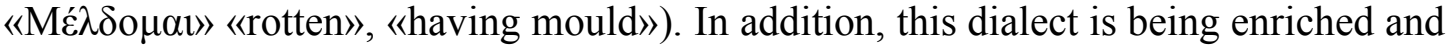
diversified by the thousands of Cypriots of the diaspora, who use the Cypriot dialect

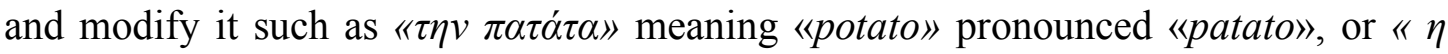
$\alpha \gamma o \rho \alpha ́$ » meaning «the market» becomes «marketa» etc.

In regards to social acceptance, one needs to observe the oxymoron, an actual ongoing situation in many countries: although, this home learned dialect is a de facto custom and practice for Cypriots, there are indications that young Cypriots tend to consider it as a variety of lower register and therefore, as an index of lower social status; to remedy its effect, young Cypriots attempt to modify their pronunciation in order to 
resemble that of the official Modern Greek. This phenomenon affects all rural areas where dialects or idioms might be traditionally spoken. It emanates from the influence of the Internet, the penetration of modernism in the most remote rural areas and seriously affects all dialects in all languages. A clean cut accent is nowadays believed to bestow a high social status upon its speaker and better prospective for work.

The article 21 of the Chart of Basic Rights of the European Union states, among others, that the respect to the linguistic diversity, is a core European Union, value. The European Union «speaks» more than 24 languages. In some countries, the official language is the same spoken by the majority (99\% in Greece and Hungary), while in others, the official language coexists with one or two more as is the case of Spain (Castellano is the formal one); in Cyprus there are three official ones and one vernacular; the official ones appear on all public documents such as IDs, Driving Licences, Court Decisions etc.

Finally, a striking example, of remarkable adaptation and inspiration in Cypriot is

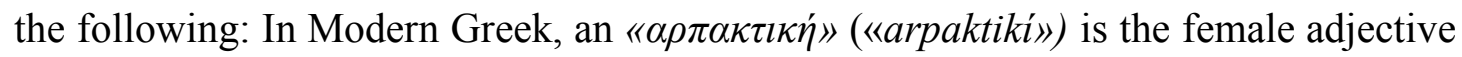
for «preditor», yet in the Cypriot dialect it is not: in the expression «Пi $\alpha$ ' $\mu o v \tau \eta v$ $\alpha \rho \pi \alpha \kappa \tau \iota \kappa \eta \dot{v} ! »$ («Bring me the arpaktikin!») the speaker does not ask for a preditor to be brought in but, for a photographic camera! Back in the '50s, KODAK advertised its cameras using the moto «Catch the Moment»! Therefore, the object that could «catch the time» became a «catcher» of the time and the moment but in Modern Greek it still is a «preditor».

Cypriot as all other dialects and idioms, is indeed an impressive and unique dialect that needs to be respected, honoured, cherished and preserved for future generations to come; mocking about it, discriminating because of it, stigmatizing anyone for its linguistic past or present should not be an option, or a Directive, or a global guideline; dialects need to be preserved as inalienable tangible and intangible monuments of our global knowledge, ethos and respect for multiculturalism and plurilinguism. Cypriot is one of them.

\section{References}

Fliatouras, A. (2018). The Morphological Change in the Greek Language. Athens: Patakis Publishing. 
Hadjioannou, X., Tsiplakou, S. \& Kappler, M. (2011). Language Policy and Language Planning in Cyprus. Current Issues in Language Planning. doi: 10.1080/14664208.2011.629113.

Kontosopoulos, N. G. (2001). Dialects and Idioms of Modern Greek (3rd edition). Athens: Grigoris Publishing.

Papanastasiou, G. (2015). The actual situation of Modern Greek dialects, in M. Tzakosta (ed.). The instruction of Modern Greek varieties and dialects at the elementary and high school level education system. Athens: Gutenberg.

Tsiplakou, S. (2006). Cyprus: language situation. In K. Brown (ed.) Encyclopedia of Language and Linguistics. 2nd Edition, (337-339). Oxford: Elsevier.

Xydopoulos, I. G. (2017). Elements of Modern Greek Dialects. Athens: Patakis Publishing. 